\title{
Anatomical and Functional Results of Pelvic Organ Prolapse Mesh Repair: A Prospective Study of 105 Cases
}

\author{
Vigen Malkhasyan*, Malika Dzhuraeva, George Kasyan, Dmitry Pushkar \\ University Clinic of Urology, Moscow State University of Medicine and Dentistry Named After A.I. Evdokimov, Moscow, Russia
}

Email address:

vigenmalkhasyan@gmail.com (V. Malkhasyan)

${ }^{*}$ Corresponding author

\section{To cite this article:}

Vigen Malkhasyan, Malika Dzhuraeva, George Kasyan, Dmitry Pushkar. Anatomical and Functional Results of Pelvic Organ Prolapse Mesh Repair: A Prospective Study of 105 Cases. International Journal of Clinical Urology. Vol. 2, No. 1, 2018, pp. 20-24.

doi: $10.11648 /$ j.ijcu.20180201.14

Received: July 17, 2018; Accepted: August 10, 2018; Published: September 12, 2018

\begin{abstract}
Objective: We assess the anatomical and functional results of pelvic organ prolapse (POP) repair with application of transvaginal synthetic meshes. Keywords: pelvic organ prolapse, vaginal repair, urogynecology. Methods: We analyzed a cohort of 105 women who underwent transvaginal pelvic floor repair using mesh (Elevate Prolapse Repair System). A gynecological examination, cough test, uroflowmetry and an administration of the overactive bladder Awareness Tool were done. Parametric and nonparametric methods of descriptive statistics, as well as logistic regression were used for data analysis. Results: Prolapse recurrence after vaginal repair was noted in $3.81 \%(\mathrm{n}=4)$ of patients. The proportion of patients with de novo onset of incontinence after surgery was $8.57 \%(n=9)$. In $26.7 \%(n=28)$ of women with stress urinary incontinence (SUI), SUI symptoms persisted after surgery. The mean $\mathrm{Q}_{\max }$ in the patient group was $19.5 \mathrm{ml} / \mathrm{s}$. The mean $\mathrm{Q}_{\max }$ in patients reporting bladder-emptying problems was $14 \mathrm{ml} / \mathrm{s}$, and the mean post-void residual (PVR) was $50 \pm 15.0 \mathrm{ml}$. After surgery, the mean $\mathrm{Q}_{\max }$ increased to $27.6 \mathrm{ml} / \mathrm{s}$. The PVR after surgery decreased to $30 \pm 5.0 \mathrm{ml}$. The number of patients with bladder outlet obstruction symptoms decreased to 17 (16.19\%). Conclusion: The management of genital prolapse with synthetic prostheses interposed through vaginal approach is an efficient method with good midterm outcomes.
\end{abstract}

Keywords: Functional Results, Overactive Bladder, Pelvic Organ Prolapse, Stress Urinary Incontinence, Vaginal Mesh

\section{Introduction}

Pelvic organ prolapse (POP) is a significant problem in modern urogynecology. The lifetime risk of a single surgery for prolapse or incontinence repair in the population under 80 years old is approximately $11.1 \%$ [1]. Each year, approximately 200,000 women undergo inpatient procedures for prolapse in the United States [2]. According to Krasnopolsky et al., in Russia, POP accounts for 28\%-39.8\% of all gynecological diseases [3]. Most frequently, pelvic organ prolapse is associated with lower urinary tract symptoms, including urinary incontinence, urgency, and bladder emptying problems. Recent literature suggests that prolapse surgery may lead to the onset of lower urinary tract symptoms, whereas in other cases, prolapse surgery can cure lower urinary tract symptoms. Thus, the current research study aimed to assess the anatomical and functional state of the lower urinary tract before and after prolapse surgery and to clarify the relationship between this prolapse and other factors.

\section{Material and Methods}

We analyzed the anatomical and functional outcomes of 105 women with symptomatic POP who underwent transvaginal pelvic floor repair using mesh (Elevate Prolapse Repair System) at our clinic between January 2009 and June 2010. All patients treated using mesh were included in the study. The exclusion criteria were as follows: women with an isolated rectocele, prolapse recurrence, disruption of the normal anatomy of the pelvis due to previous injuries or surgeries and the need for a concomitant hysterectomy. We analyzed a cohort of 105 consecutive patients. Before and 12 months after surgical treatment, all patients participated in a comprehensive survey. All patients underwent a standardized interview in which data such as age, the number of deliveries, hysterectomies, and cesarean sections and the patient's body 
mass index (BMI) were evaluated. To evaluate the symptoms of overactive bladder (OAB), we used the Russian version of the OAB Awareness Tool. To evaluate the bladder outlet obstruction symptoms (BOO), we used the Russian version of the IPSS questionnaire. POP was quantified pre- and postoperatively using the POP-quantification (POP-Q) system. In addition, a cough test (with bladder distention up to $150 \mathrm{ml}$ ) was performed pre- and postoperatively. We also performed uroflowmetry (with bladder distention up to 150 $\mathrm{ml}$ ) three times pre- and postoperatively. This study was approved by an Ethics Committee.

The mean age of the patients was 65.8 years (range: $45-84$ years). Of a total of 105 patients, 14 patients had stage IV $(13.3 \%)$ and 91 patients had stage III (86.7\%) vaginal prolapse. Total mesh interposition was performed for cystorectocele in $84(80.0 \%)$ patients, and anterior compartment repair was performed in 21 patients $(20.0 \%)$ with cystocele. The mean BMI was $27.5 \mathrm{~kg} / \mathrm{m}^{2}$ (range: $17-40$ $\mathrm{kg} / \mathrm{m}^{2}$ ). The mean number of deliveries was 1.6 (range: $0-3$ ). Ten patients had previously undergone a hysterectomy. The mean $\mathrm{Q}_{\max }$ in the general group was $19.5 \mathrm{ml} / \mathrm{s}(4.5-62 \mathrm{ml} / \mathrm{s})$. Fifty-seven women $(54.3 \%, 95 \% \mathrm{CI}=44.28-64.04 \%)$ reported voiding difficulties (more than 19 points on the IPSS questionnaire). The proportion of patients with urinary incontinence was 37.14\% $(\mathrm{n}=39 ; 95 \% \mathrm{CI}=27.91-47.12 \%)$. Moreover, $61.5 \%(n=24)$ of these patients, or $22.86 \%$ of all patients, exhibited clinical manifestations of urinary incontinence at the time of admission, and in the $38.5 \%$ $(n=15)$ of patients exhibiting urinary incontinence $(14.29 \%$ of all patients), urinary incontinence was revealed by manual reduction of prolapse during a vaginal examination before surgery (occult stress incontinence). Symptoms of $\mathrm{OAB}$ (more than 8 points on the OAB Awareness Tool questionnaire) were reported by $53.33 \% \quad(n=56) \quad(95 \%$ $\mathrm{CI}=43.34-63.13 \%$ ) of patients slated for surgery.

To assess differences between two dependent groups, we used the 95\% Clopper-Pearson binomial confidence interval (CI) comparison method. To confirm the statistical hypotheses, nonparametric McNemar (chi-square) tests were used. The Wilcoxon signed-rank test (non-parametric statistical hypothesis test) was used to compare two related groups. A p value less than 0.05 was considered statistically significant. To describe the relationship between two binary traits, we used the odds ratio (OR). To assess the relationship between quantitative and binary traits, the logistic regression coefficient was calculated.

\section{Results}

Prolapse recurrence after vaginal repair was noted in $3.81 \% \quad(n=4) \quad(95 \% \quad \mathrm{CI}=1.05-9.475 \%) \quad$ of patients. Approximately $96.19 \%$ of patients exhibited anatomically satisfactory results $(n=101)(95 \% \quad C I=90.53-98.95 \%)$. The difference between groups was significant because the CIs did not overlap.

As shown in Table 1, after surgery, patients noted significant improvements in symptoms such as bulging, difficulty in bladder emptying, urgent incontinence, urinary frequency, and nocturia.

After prolapse repair, urinary incontinence resolution was noted in $10.48 \%(\mathrm{n}=11)(95 \% \mathrm{CI}=5.35-17.97 \%)$ of patients. Among them, 9 women $(8.57 \%$ of all patients and $23.08 \%$ of women with incontinence) suffered from symptoms of incontinence before surgery, and in 2 patients $(1.9 \%$ of all patients and $5.13 \%$ of women with incontinence) occult stress urinary incontinence (SUI) was revealed during a preoperative examination. The proportion of patients with de novo onset of incontinence after surgery was $8.57 \%(\mathrm{n}=9)$ (95\% CI=3.99-15.65\%). In 26.7\% ( $\mathrm{n}=28)$ of women with SUI, SUI symptoms persisted after surgery. We observed no statistically significant difference when comparing the proportion of women with SUI before $(37.14 \%, n=39,95 \%$ $\mathrm{CI}=27.91-47.12 \%)$ and after surgery $(35.24 \%, \mathrm{n}=37,95 \%$ $\mathrm{CI}=26.16-45.17 \%$ ), as the CIs overlapped. The application of the McNemar test $(p=0.8231)$ also revealed no statistically significant difference between the pre- and postoperative values $(95 \% \mathrm{CI}=0.300-2.172)$.

Table 1. Symptoms before and after surgery.

\begin{tabular}{|c|c|c|c|c|c|c|}
\hline & Before surgery & & & After surgery & & \\
\hline Complaint & No. of patients & Proportion & $95 \% \mathrm{CI}^{\mathrm{a}}$ & No. of patients & Proportion & $95 \% \mathrm{CI}$ \\
\hline Bulging symptoms & 72 & 68.57 & $58.78-77.28$ & 7 & 6.67 & $2.72-13.25$ \\
\hline Bladder emptying problems & 32 & 30.48 & $21.87-40.22$ & 9 & 8.57 & $3.99-15.65$ \\
\hline Urinary frequency and nocturia & 56 & 53.33 & $43.34-63.13$ & 24 & 22.86 & $15.23-32.07$ \\
\hline Urgency & 56 & 53.33 & $43.34-63.13$ & 24 & 22.86 & $15.23-32.07$ \\
\hline Stress urinary incontinence & 24 & 22.86 & $15.23-32.07$ & 24 & 22.86 & $15.23-32.07$ \\
\hline Urgent incontinence (at least 1 time) & 12 & 11.43 & $6.05-19.11$ & 5 & 4.76 & $1.56-10.76$ \\
\hline
\end{tabular}

a $95 \% \mathrm{CI}-95 \%$ confidence interval

The mean $\mathrm{Q}_{\max }$ in the patient group was $19.5 \mathrm{ml} / \mathrm{s}$ (range: 4.5-62 $\mathrm{ml} / \mathrm{s}, \mathrm{Me}=19.5 \mathrm{ml} / \mathrm{s})$. Fifty-seven (54.3\%) patients reported voiding difficulties (more than 19 points on the IPSS questionnaire). The mean $\mathrm{Q}_{\max }$ in patients reporting bladder-emptying problems was $14 \mathrm{ml} / \mathrm{s}$ (range: 4.5-19.9 $\mathrm{ml} / \mathrm{s}, \mathrm{Me}=6 \mathrm{ml} / \mathrm{s}$ ), and the mean post-void residual (PVR) was $50 \pm 15.0 \mathrm{ml}$. After surgery, the mean $\mathrm{Q}_{\max }$ increased to
$27.6 \mathrm{ml} / \mathrm{s}$ (range: $58-15.6 \mathrm{ml} / \mathrm{s}, \mathrm{Me}=26.1 \mathrm{ml} / \mathrm{s}$ ). In patients with bladder emptying problems, this value increased to 26 $\mathrm{ml} / \mathrm{s}(\mathrm{Me}=26 \mathrm{ml} / \mathrm{s})$. The PVR after surgery decreased to $30 \pm 5.0 \mathrm{ml}$. The number of patients with bladder outlet obstruction (BOO) symptoms decreased to 17 (16.19\%). A comparison of patients with BOO symptoms before $(54.3 \%$, $\mathrm{n}=57,95 \% \mathrm{CI}=44.28-64.04 \%)$ and after $(16.19 \%, \mathrm{n}=17,95 \%$ 
$\mathrm{CI}=9.72-24.65 \%$ ) surgery revealed no CI overlap. This finding suggests that the difference between the values before and after surgery is statistically significant. The difference in
$\mathrm{Q}_{\max }$ between the two groups was $6.6 \mathrm{ml} / \mathrm{s}$. A Wilcoxon signed-rank test $(\mathrm{p}<0.001)$ indicated a high level of statistical significance (Figure 1).

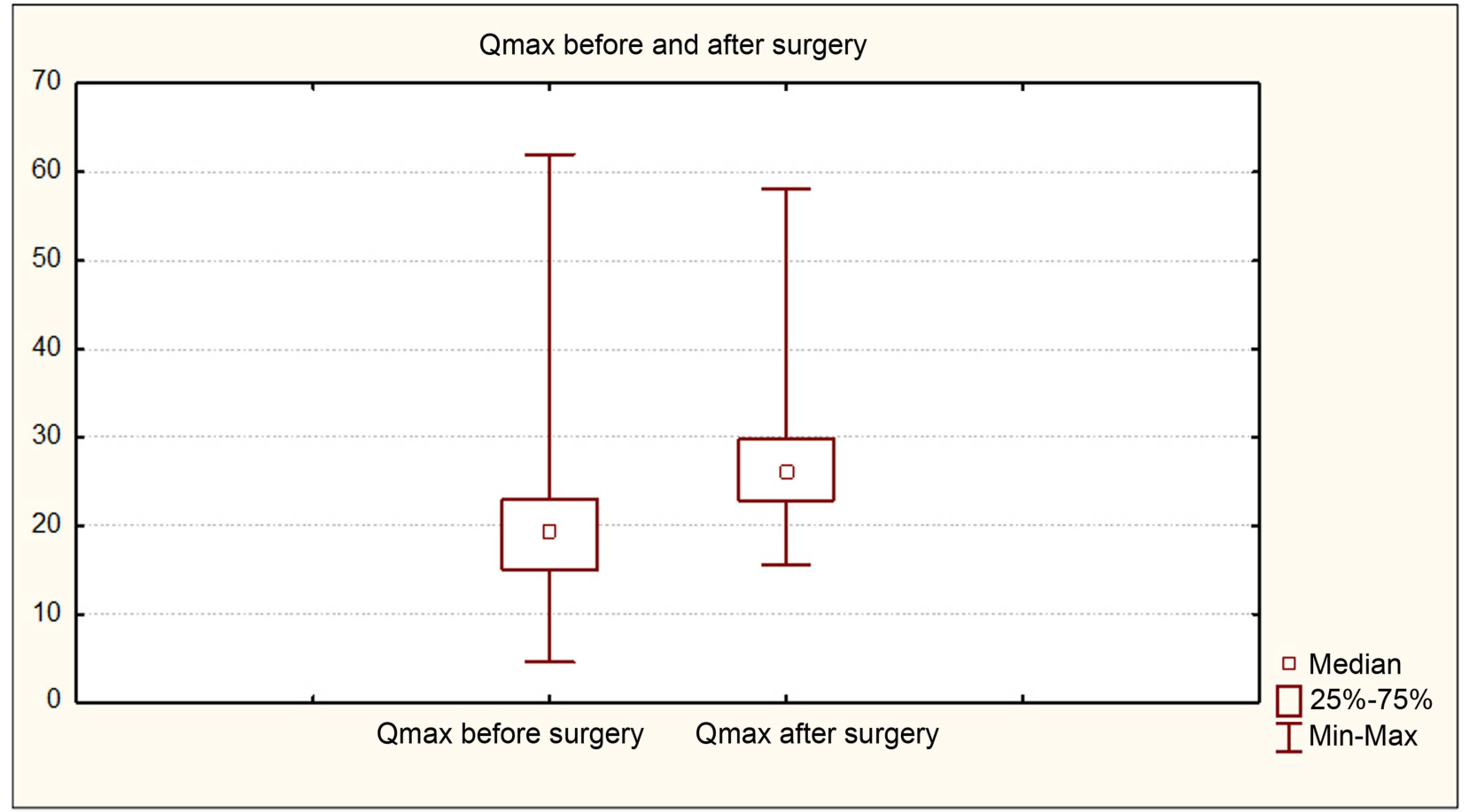

Figure 1. $Q_{\max }$ before and after surgery.

The lower quartile was $15 \mathrm{ml} / \mathrm{s}$ before surgery and $22.8 \mathrm{ml} / \mathrm{s}$ after surgery. The upper quartile was $22.9 \mathrm{ml} / \mathrm{s}$ before surgery and $29.8 \mathrm{ml} / \mathrm{s}$ after surgery. $\mathrm{Q}_{\max }-$ maximum urinary flow rate

As noted above, 53.33\% ( $\mathrm{n}=56,95 \% \mathrm{CI}=43.34-63.13 \%)$ of patients reported $\mathrm{OAB}$ symptoms (more than 8 points on the OAB Awareness Tool questionnaire) before surgery. Among 56 women with OAB symptoms, $64.29 \%(n=36,34.29 \%$ of all patients) noted symptom resolution after surgery. In addition, $3.81 \% \quad(n=4)$ reported de novo onset of OAB symptoms. Thus, the proportion of women with $\mathrm{OAB}$ symptoms before surgery decreased from $53.33 \%(\mathrm{n}=56)$ to $22.86 \% \quad(n=24)(95 \% \quad C I=15.23-32.07 \%)$ after surgery. A comparison of the CIs of these values revealed no overlap. The statistical significance between these two groups was also confirmed by a McNemar test $(\mathrm{p}=0.0001, \mathrm{OR}=0.111$, 95\% CI=0.029-0.310).
We assessed the relationship between BOO symptoms and POP stage by calculating the OR, which was 3.587 (95\% $\mathrm{CI}=0.9-13.7)$. This finding indicates a 3.5 -fold increased risk of BOO symptoms in patients with POP-Q IV than in patients with POP-Q III. The OR for the relationship between the $\mathrm{OAB}$ and $\mathrm{BOO}$ was $15.89(95 \% \mathrm{CI}=6-41.4)$, which indicated a 15-fold increased risk of OAB symptoms in patients suffering from BOO symptoms. We also analyzed the relationship between SUI and OAB symptoms before and after surgery using the factors BMI, age, $\mathrm{Q}_{\max }$, number of deliveries, and the number of cesarean sections. The results are presented in Table 2 .

Table 2. Relationship between the functional state of pelvic organs and other factors.

\begin{tabular}{llll}
\hline Symptom & Factor & Relationship & p \\
\hline Urinary incontinence before surgery & Deliveries & ++ & 0.0000 \\
Urinary incontinence after surgery & $\mathrm{BMI}^{\mathrm{a}}$ & ++ & 0.0000 \\
Urinary incontinence after surgery & Deliveries & + & 0.0004 \\
OAB $^{\mathrm{b}}$ symptoms before surgery & $\mathrm{Q}_{\max }{ }^{c}<20 \mathrm{ml} / \mathrm{s}$ & ++ & 0.0000 \\
OAB symptoms after surgery & $\mathrm{Q}_{\max }$ & + & 0.0004 \\
POP-Q $^{\mathrm{d}}$ stage before surgery & $\mathrm{Age}$ & ++ & 0.0000 \\
\hline
\end{tabular}

${ }^{\mathrm{a}} \mathrm{BMI}$ - body mass index

${ }^{\mathrm{b}} \mathrm{OAB}$ - overactive bladder

${ }^{\mathrm{c}} \mathrm{Q}_{\max }-$ maximum urinary flow rate

${ }^{\mathrm{d}}$ POP-Q - Pelvic Organ Prolapse Quantification System

The analysis revealed a strong statistically significant relationship between the number of deliveries and urinary 
incontinence symptoms. This finding suggests an increased risk of urinary incontinence in women with a history of more than two deliveries. We also found a statistically significant association among SUI symptoms after surgery, BMI and the number of deliveries. This finding indicates an increased risk of experiencing SUI symptoms after surgery in obese women and in women with a history of more than two deliveries. We observed a strong statistically significant relationship between the POP-Q stage and the age of the patient. Thus, we can conclude that the risk of progression of the POP-Q stage increases with age. We also observed a strong correlation between the $\mathrm{Q}_{\max }$ and $\mathrm{OAB}$ symptoms before and after surgery. Due to this direct correlation, $\mathrm{Q}_{\max }$ improvement might be considered a predictive factor for the postoperative improvement of OAB symptoms.

\section{Discussion}

Recent literature suggests that genital prolapse may cause detrusor overactivity. Rosenzweig et al. reported remission of $\mathrm{OAB}$ symptoms after surgical correction of prolapse in $85 \%$ of patients [4]. In another study, Enhorning et al. reported that the incidence of detrusor instability in women with severe prolapse (III-IV) was 52\% compared with $20 \%$ in patients suffering from stage I-II prolapse [5]. Boer et al. [6] reported a higher prevalence of $\mathrm{OAB}$ symptoms in patients with POP compared with patients without POP. The authors also suggested that POP surgery resulted in an improvement of $\mathrm{OAB}$ symptoms and reported that bladder outlet obstruction is likely the most important mechanism by which POP induces OAB symptoms and detrusor overactivity (DO) signs. These data have also been confirmed by Basu et al. [7], who examined forty women undergoing prolapse repair with $\mathrm{OAB}$ and detrusor overactivity in conjunction with anterior wall prolapse. The authors noted that the resolution of OAB was associated with a significant increase $(p=0.049)$ in the $\mathrm{Q}_{\max }$ value. Digesu et al. [8] prospectively evaluated ninetythree consecutive women with symptomatic anterior vaginal wall prolapse $\geq$ stage II and coexistent overactive bladder symptoms. Postoperatively, urinary frequency, urgency and urgent incontinence were resolved in $60 \%, 70 \%$ and $82 \%$ of women, respectively $(p<0.001)$. In our study, we obtained very similar results. Mesh surgery improved the urinary flow rate in $38.11 \%$ of women and increased the mean $\mathrm{Q}_{\max }$ value by $6.6 \mathrm{ml} / \mathrm{s} \quad(\mathrm{p}<0.0001)$. In addition, after surgery, OAB symptom resolution was observed in $64.29 \%$ of patients. These results confirmed that bladder outlet obstruction due to POP is likely the cause of OAB symptoms and DO signs. Therefore, we believe that $\mathrm{POP}$ repair in patients with $\mathrm{BOO}$ signs should result in significant improvement in voiding after surgery. Furthermore, when planning interventions, BOO prolapse could serve as a favorable factor for $\mathrm{OAB}$ symptom resolution. Hiltunen et al. [9] reported the same incidence of de novo SUI onset $(9.3 \%)$ after surgery for cystocele with or without a mesh implant. It has been assumed that prolapse surgery can provoke the onset of occult SUI. Despite this fact, recent studies have reported contrasting data, describing the resolution of stress incontinence after pelvic organ prolapse repair. Borstad et al. [10] published a multicenter prospective randomized trial in which women with POP and SUI were randomized to groups that received tension-free vaginal tape (TVT) at the time of prolapse repair ( $\mathrm{n}=87$; group I) or 3 months later $(\mathrm{n}=94$; group II). According to results of this study, twenty-seven percent were cured after prolapse surgery alone. In our study, the results were similar; $28.21 \%$ of women with SUI noted complete symptom resolution postoperatively.

\section{Conclusion}

According to the results of our study, mesh surgery is an efficient method of treatment and results in a low recurrence rate (less than $3.81 \%$ ). Mesh surgery resulted in SUI symptom reduction in $28.21 \%$ of patients; at the same time, it triggered the onset of SUI symptoms in $23.08 \%$ of women. Mesh surgery improved the urinary flow rate in $38.11 \%$ of cases and increased the $\mathrm{Q}_{\max }$ value by $6.6 \mathrm{ml} / \mathrm{s}(\mathrm{p}<0.0001)$. After surgery, $\mathrm{OAB}$ symptoms were resolved in $64.29 \%$ of cases. Women with a history of more than two deliveries exhibited a higher risk of SUI. Age is a risk factor for progression of pelvic organ prolapse. Obese women with a history of more than two deliveries are at a higher risk of persistence or de novo SUI onset after surgery. A strong relationship was observed between the $\mathrm{Q}_{\max }$ value and $\mathrm{OAB}$ symptoms before and after surgery. Therefore, $\mathrm{Q}_{\max }$ improvement is correlated with improvement in $\mathrm{OAB}$ symptoms. Thus, $\mathrm{Q}_{\max }$ improvement could explain the mechanism and in some cases might be considered a predictive factor for the postoperative improvement of OAB symptoms.

\section{Conflict of Interest Statement}

The authors declare that they have no conflict of interest

\section{References}

[1] Olsen AL, Smith VJ, Bergstrom JO et al. Epidemiology of surgically managed pelvic organ prolapse and urinary incontinence. Obstet Gynecol 1997; 89:501-506. [Journal]

[2] Boyles S, Weber A, Meyn L. Procedures for pelvic organ prolapse in the United States, 1979-1997. Am J Obstet Gynecol 2003; 188:108-115. [Journal]

[3] Krasnopolsky VI, Ioseliani MN, Rizhinashvili ID et al. [Contemporary aspects of surgical treatment of descent and prolapse of female genital organs]. [Article in Russian] Obstet Gynecol (Russia) 1990; 8:58-61. [Journal]

[4] Rosenzweig BA. Genital prolapse and lower urinary tract dysfunction. Int Urogynecol J Pelvic Floor Dysfunct 1993; 4:296-300. [Journal]

[5] Enhorning GE. Simultaneous recording of intravesical and intraurethral pressure: a study of urethral closure in normal and stress incontinent women. Eur J Surg Suppl 1961;276:168. [Journal] 
[6] De Boer TA, Salvatore S, Cardozo L et al. Pelvic organ prolapse and overactive bladder. Neurourol Urodyn 2010; 29:30-39. [Journal]

[7] Basu M, Duckett J. Effect of prolapse repair on voiding and the relationship to overactive bladder and detrusor overactivity. Int Urogynecol J Pelvic Floor Dysfunct 2009; 20:499-504. [Journal]

[8] Digesu GA, Salvatore S, Chaliha $\mathrm{C}$ et al. Do overactive bladder symptoms improve after repair of anterior vaginal wall prolapsed? Int Urogynecol J Pelvic Floor Dysfunct 2007; 18:1439-1443. [Journal]
[9] Nieminen $K$, Hiltunen $R$, Takala $T$ et al. Outcomes after anterior vaginal wall repair with mesh: a randomized, controlled trial with a 3 year follow-up. Am J Obstet Gynecol 2010; 203:235-e1. [Journal]

[10] Borstad E, Abdelnoor M, Staff AC et al. Surgical strategies for women with pelvic organ prolapse and urinary stress incontinence. Int Urogynecol J Pelvic Floor Dysfunct 2010; 21:179-186. [Journal] 